\title{
Corrigendum to "Under-the-Flap Crosslinking and LASIK in Early Ectasia with Hyperopic Refractive Error"
}

\author{
Sylvain el-Khoury $\mathbb{D}^{1,2}$, ${ }^{1,2}$ oussef Abdelmassih $\mathbb{D}^{1,},{ }^{1,2}$ Mazen Amro, ${ }^{1,3}$ Elias Chelala, ${ }^{1,2}$ \\ and Elias Jarade $\mathbb{D D}^{1,4}$ \\ ${ }^{1}$ Beirut Eye Specialist Hospital, P.O. Box 116-5311, Al-Mathaf Square, Beirut, Lebanon \\ ${ }^{2}$ Saint-Joseph University, Faculty of Medicine, Beirut, Lebanon \\ ${ }^{3}$ School of Medical Sciences, Lebanese University, Beirut, Lebanon \\ ${ }^{4}$ Mediclinic Dubai Mall, Dubai, UAE \\ Correspondence should be addressed to Elias Jarade; ejarade@yahoo.com
}

Received 28 May 2019; Accepted 10 June 2019; Published 14 July 2019

Copyright (c) 2019 Sylvain el-Khoury et al. This is an open access article distributed under the Creative Commons Attribution License, which permits unrestricted use, distribution, and reproduction in any medium, provided the original work is properly cited.

In the article titled "Under-the-Flap Crosslinking and LASIK in Early Ectasia with Hyperopic Refractive Error" [1], there was a missing reference [2] that should have been included in the reference list as reference [33]. Accordingly, the fifth paragraph in Introduction should be updated as follows:

"To prevent the development of post-LASIK ectasia in the eyes at high risk, Kanellopoulos et al. introduced the LASIK Xtra technique (Avedro, Massachusetts, USA) in 2012 [14]. In this technique, prophylactic high irradiation CXL is performed in adjunction to the LASIK procedure and without deepithelisation. Several studies demonstrated this procedure to be safe and effective, to show less regression and to have less discomfort [15-17]. A recent study has described a similar technique for the eyes that have already developed a post-LASIK ectasia. The old LASIK flap is lifted again, and the CXL is performed under the flap. This procedure keeps the epithelium intact, and preliminary results are promising [33]."

This error was brought to the authors' attention in response to a letter received on their article [3].

\section{References}

[1] S. el-Khoury, Y. Abdelmassih, M. Amro, E. Chelala, and E. Jarade, "Under-the-flap crosslinking and LASIK in early ectasia with hyperopic refractive error," Journal of Ophthalmology, vol. 2018, Article ID 4342984, 10 pages, 2018.
[2] A. Wallerstein, E. Adiguzel, M. Gauvin, N. Mohammad-Shahi, and M. Cohen, "Under-flap stromal bed CXL for early postLASIK ectasia: a novel treatment technique," Clinical Ophthalmology, vol. 11, pp. 1-8, 2016.

[3] Avi Wallerstein, Mathieu Gauvin, and Mark Cohen, "Comment on "Under-the-flap crosslinking and LASIK in Early Ectasia with Hyperopic Refractive Error"," Journal of Ophthalmology, vol. 2019, Article ID 4986597, 2 pages, 2019. 


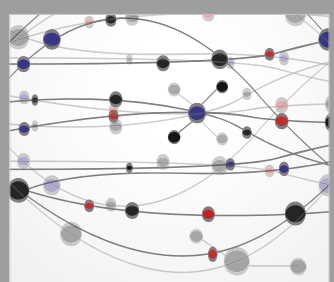

The Scientific World Journal
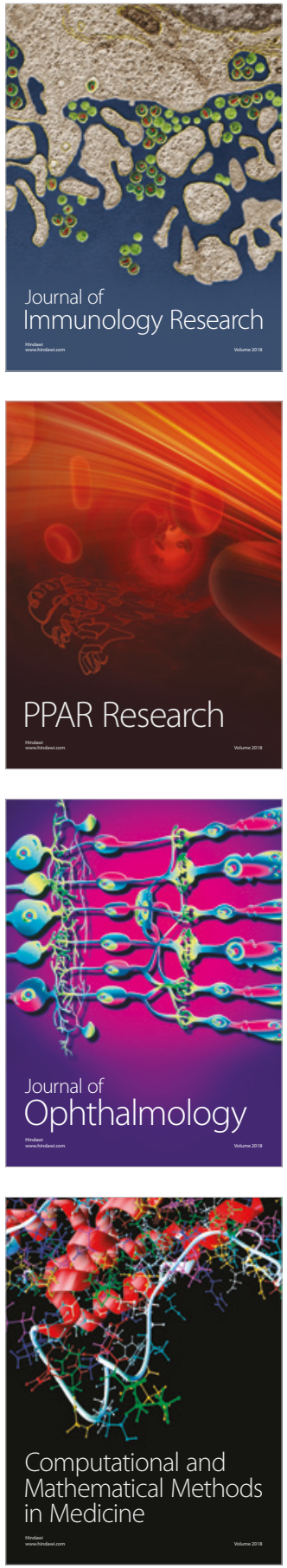

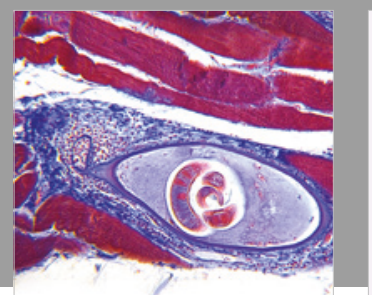

Gastroenterology Research and Practice

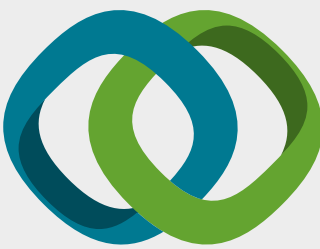

\section{Hindawi}

Submit your manuscripts at

www.hindawi.com
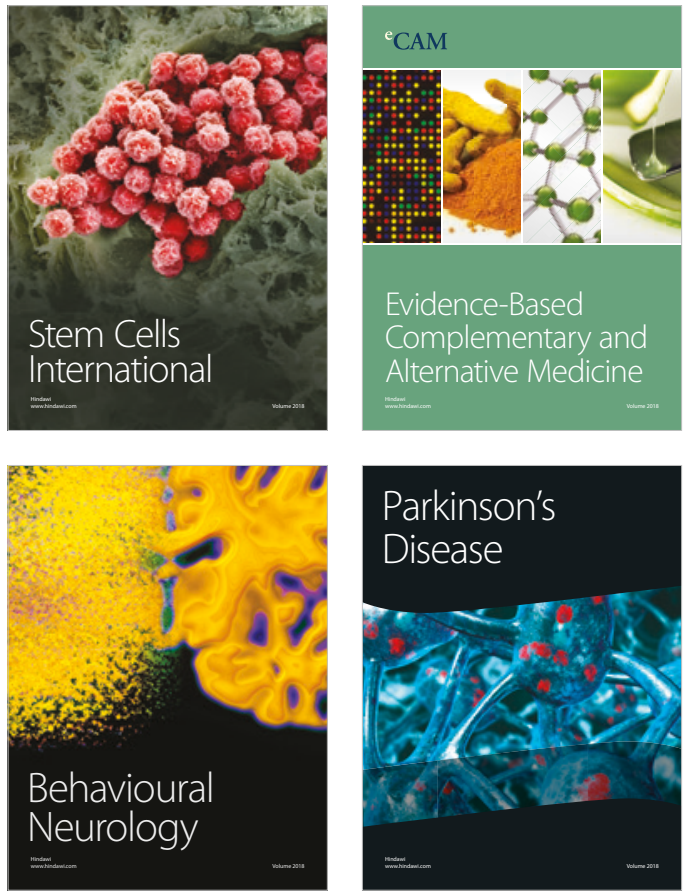

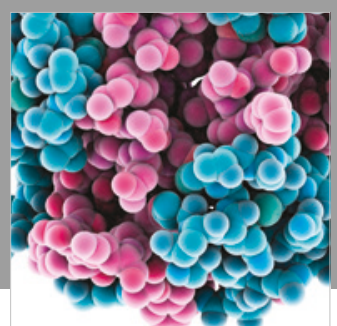

ournal of

Diabetes Research

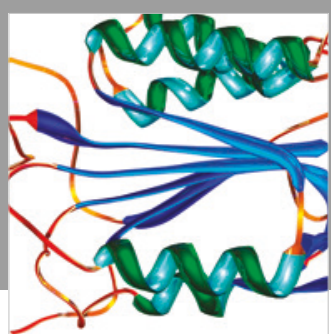

Disease Markers
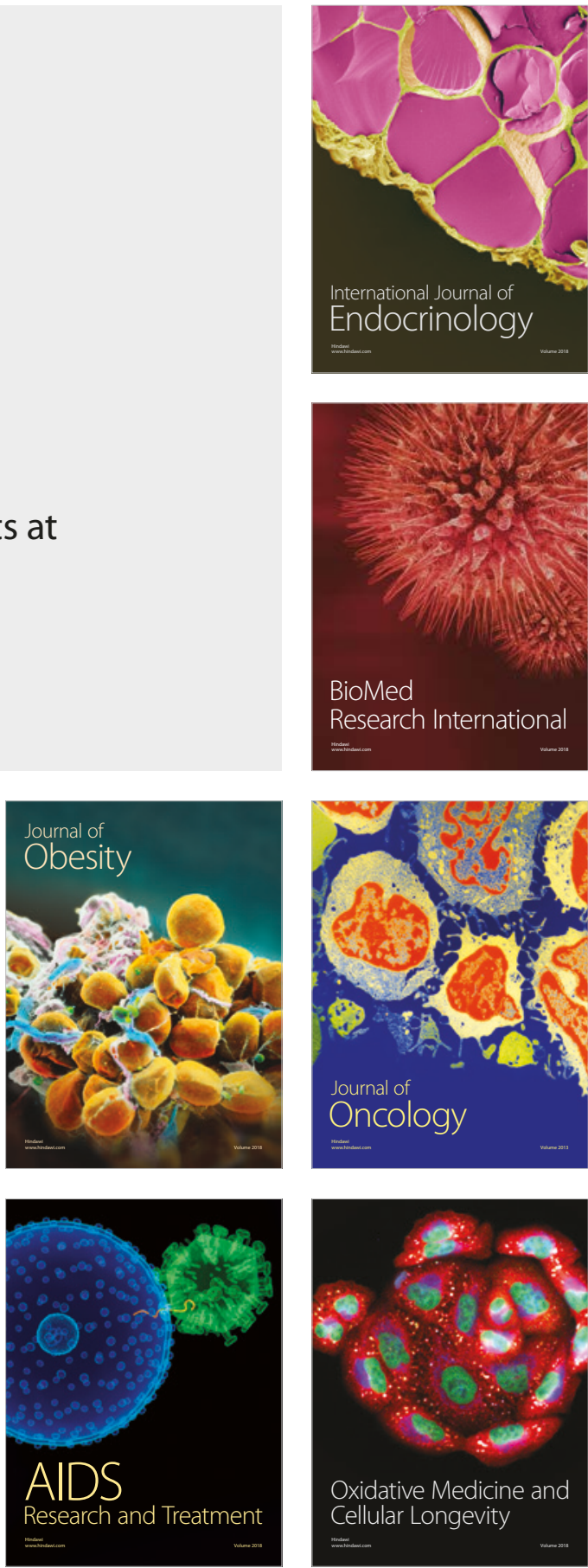